\title{
Implementation of inquiry-based science education in different countries: some reflections
}

\author{
Carl-Johan Rundgren ${ }^{1}$
}

Received: 2 September 2015/Accepted: 14 September 2016/Published online: 20 March 2017

(C) The Author(s) 2017. This article is an open access publication

\begin{abstract}
In this forum article, I reflect on issues related to the implementation of inquirybased science education (IBSE) in different countries. Regarding education within the European Union (EU), the Bologna system has in later years provided extended coordination and comparability at an organizational level. However, the possibility of the EU to influence the member countries regarding the actual teaching and learning in the classrooms is more limited. In later years, several EU-projects focusing on IBSE have been funded in order to make science education in Europe better, and more motivating for students. Highlighting what Heinz and her colleagues call the policy of 'soft governance' of the EU regarding how to improve science education in Europe, I discuss the focus on IBSE in the seventh framework projects, and how it is possible to maintain more longlasting results in schools through well-designed teacher professional development programs. Another aspect highlighted by Heinz and her colleagues is how global pressures on convergence in education interact with educational structures and traditions in the individual countries. The rise of science and science education as a global culture, encompassing contributions from all around the world, is a phenomenon of great potential and value to humankind. However, it is important to bear in mind that if science and science education is going to become a truly global culture, local variation and differences regarding foci and applications of science in different cultures must be acknowledged.
\end{abstract}

Keywords Science education · Inquiry-based science education · Comparative study

Lead editor: K. Scantlebury.

This article responds to issues raised in J. Heinz, M. Enghag, I. Stuchlikova, G. Cakmakci, R. Peleg \& A. Baram-Tsabari (this issue) Impact of initiatives to implement science inquiry: a comparative study of the Turkish, Israeli, Swedish, and Czech science education systems. doi:10.1007/s11422-015-9704-6.

Carl-Johan Rundgren

carl-johan.rundgren@mnd.su.se

1 Department of Mathematics and Science Education, Stockholm University, 10691 Stockholm, Sweden 
The article published by Jana Heinz, Margareta Enghag, Iva Stuchlikova, Gultekin Cakmakci, Ran Peleg and Ayelet Baram-Tsabari (this issue) raises many interesting ideas about the implementation of inquiry-based science education (IBSE) in different countries. This type of comparative studies can in my view contribute to building an empirical basis for discussing cultural differences and similarities in science education among different countries. As science in school has its own history in each country, naturally influenced by major international trends, but in each country following its own socio-historical course, comparisons between different educational systems become inherently difficult. The political discussion on education in many countries are at present largely dominated by national performance on cross-national tests such as PISA (Programme for International Student Assessment) and TIMSS (Trends in International Mathematics and Science Study), and comparisons with the performances of other countries. Therefore, empirical studies such as Heinz and her colleagues' study, highlighting cultural constraints and possibilities of science education in the actual classrooms in different countries, are very welcome. There is a need of reflecting on the aims and ways of science education, and what education ought to be like in a particular country or context, rather than on performance ranking per se.

In the research field of comparative education, the intertwined relationships among cultural contexts and physical, social, historical, and political specificities have been acknowledged and considered for long. An important scholar within comparative education is Lawrence Stenhouse, who has highlighted the importance of social and cultural factors in education (1979). Within the field of comparative education, it is commonly argued that successful educational systems or organizational structures cannot simply be 'uprooted' and imported from one country to another without adapting it to the cultural context and to local needs (Drori 2000).

The European Union (EU) has since its establishment needed to balance the will to have national decision-making power regarding country-specific questions, and the need for coordination of policies within the union in order to make common progress in all member countries in areas such as economy, environment and education. Regarding education, the Bologna system, which provides a common system for grades and degrees within the EU, has provided extended coordination and comparability at an organizational level within education in Europe. However, regarding questions about actual teaching and learning in the classrooms, the possibilities of the EU to influence the member countries are more limited, since there is no common framework regarding curricular content at a European level. The curricula are decided at a national level, and there is no political will within the EU to strive towards cross-national curricula. Heinz and her colleagues discuss the policy of 'soft governance' of the EU regarding how to improve science education in Europe. Their article provides a reflection on the limitations and possibilities of this 'soft governance'.

\section{The 'soft governance' in education in Europe: the seventh framework projects}

Heinz and her colleagues discuss how the EU, in spite of lacking any mandatory guidelines to implement science inquiry in the member countries, tries to promote IBSE in Europe. Another aspect highlighted in their article is how global pressures on convergence in 
education interact with educational structures and traditions in the individual countries. These developments are interpreted in the light of neo-institutional theories.

In later years, several EU-projects focusing on IBSE have been funded, following the release of the Rocard report (Rocard, Csermely, Jorde, Lenzen, Walberg-Henriksson and Hemmo 2007), which highlighted the usefulness of IBSE in order to make science education in Europe better, and more motivating for students. The S-TEAM (Science-Teacher Education Advanced Methods) project, which is the project in focus in Heinz and colleagues' article, is one of these projects. The empirical data used by Heinz and her colleagues come from discussions among science educators within the S-TEAM project. One of the motives of the S-TEAM project, as well as of other seventh framework projects such as PROFILES (Professional Reflection-Oriented Focus on Inquiry-based Learning and Education through Science), ESTABLISH (European Science and Technology in Action: Building Links with Industry, Schools and Home), PARRISE (Promoting Attainment of Responsible Research and Innovation in Science Education) and others, has been to tackle the low interest in pursuing studies in science and technology. Students' declining interest in pursuing science studies at secondary level, especially in the physical sciences such as physics and chemistry, in the majority of developed countries has been a continuing problem in later decades (George 2006). The international study of the Relevance of Science Education (ROSE) has shown that 15-year-old students in developed countries find many of the themes and questions posed by science interesting and important (Jidesjö, Oscarsson, Karlsson and Strömdahl 2009), but at the same time many students fail to see school science as meaningful for their future careers and consequently reject science and technology as their main field of study (Oscarsson, Jidesjö, Strömdahl and Karlsson 2009). As a reaction to this situation, an explicit aim with the IBSE-related projects within the seventh framework program has been to make science education more relevant to young people.

Currently we do not know whether the EU's policy of encouraging and spreading the use of IBSE through projects such as S-TEAM indeed contribute to better learning of science and/or increased motivation for science and for pursuing science studies among students, and what kind of (if any) lasting impact those projects can have in the actual classrooms in different European countries. There are studies which question whether IBSE can be considered to have the expected positive effects on students' learning (Kirschner, Sweller and Clark 2006). For instance, Kerstin Bergqvist and Roger Säljö (1994) display negative learning results from open inquiry activities with little guidance from the teacher. However, several studies also report positive learning outcomes from using IBSE (Furtak, Seidel, Iverson, and Briggs 2012). Fouad Abd-El-Khalik, Saouma BouJaoude, Richard Duschl, Norman G. Lederman, Rachel Mamlok-Naaman, Avi Hofstein, Mansoor Niaz, David Treagust and Hsiao-Lin Tuan (2004) conclude that the notion of inquiry in science education is one of the few overarching themes that cut across school curricula all over the world. A conclusion that might be drawn from those studies is that the learning outcomes are more related to the way in which IBSE is conducted, the contexts of the implementation of IBSE, and how well the teachers are able to scaffold the students' learning rather than related to the use of IBSE as such (Ostermeier, Prenzel and Duit 2010).

One of the aims of the S-TEAM project was to enable large numbers of teachers to adopt advanced methods for effective science teaching. Since education often is considered to be an art, involving tacit knowledge among teachers on how to teach different learners and how to respond to upcoming questions and challenges, there can never be any guarantee of successful learning outcomes from using a specific instructional method. Like many other professional areas, teaching do not only involve the Aristotelian knowledge 
categories of episteme (generalizable, theoretical knowledge) and techne (skills), but also phronesis, which connects to what can be characterized as a kind of life-wisdom related to knowing how to act appropriately, and to act in ethically sound ways, in different situations. According to Biesta (2007), the element of phronesis in teachers' professional work makes it difficult to transfer what has been labeled 'best practices' or 'what works' from one educational context to another. However, being aware of this basic characteristic of education does not mean that we cannot make progress in terms of trying out and evaluating different strategies or designs of teaching. Research in science education (or Didaktik in the continental European tradition) can provide a knowledge-base which could help teachers in making more initiated and well-founded educational choices of using appropriate teaching strategies or teaching designs for different groups of students. However, any search for a lapis philosophorum (the legendary philosophers' stone in alchemy, which could transform ordinary substances into gold) in the form of a single instructional method that always works for any group of students, is likely to fail.

Besides improving motivation, learning, and pupil attitude in European science education, the S-TEAM project also aimed to support teachers by providing professional development. At the core of many of the seventh framework projects are in-service teacher professional development (teacher professional development, TPD, or continuous professional development, CPD). A fundamental consideration for those projects is that if there is a vision to change science education in European schools, it is not enough only to reach pre-service teachers, but we also need to reach teachers working in schools. A requirement for the projects to be successful in the long run is the continuation of teachers' professional development also after the projects themselves have ended. Since education invariably include some kind of visions for the future and entail a long-term commitment, the sustainability of those efforts to promote IBSE in Europe are central to any quality assessment of the outcome of the seventh framework projects.

\section{Inquiry as a content in teacher professional development}

Since IBSE is such an important feature of the seventh framework projects, increasing teachers' awareness of different aspects and forms of IBSE can be an important aspect of teacher professional development. Science inquiry can both be a pedagogic strategy for teaching science, and a learning content (Abd-El-Khalick et al. 2004). The inquiry process, that is, how to pose questions, formulate hypotheses, design experiments to test hypotheses, collect data, draw conclusions etc. can be regarded as an important part of learning the nature of science (NOS) (Lunde, Rundgren and Chang Rundgren 2015). However, Judith Lederman, Norman Lederman, Stephen Bartos, Selina Bartels, Allison Antink Meyer and Renee Schwartz (2014) argue that there is an important distinction between science inquiry and NOS. They stress that NOS embodies the characteristics of science and what differentiates science from other disciplines, while science inquiry is the process of how scientists do their work and how the resulting science knowledge is generated and accepted. Thus, there is a double risk of conflation of inquiry as a pedagogic strategy and as a learning content, and of science inquiry and NOS. Heinz and her colleagues highlight the ambiguity of the term science inquiry (Furtak et al. 2012) and discuss inquiry as three different ideas in education: (1) a set of skills to be learned by the students; (2) a cognitive understanding of the processes of inquiry, for example the logic of a controlled experiment; and (3) a pedagogical strategy. Inquiry could also take forms other 
than for example gathering experimental data in the lab or from field studies. For instance, socio-scientific inquiry could entail searching information from mass media or performing interviews with stakeholders. The expansion within science education of the field of socioscientific issues (Zeidler 1997) in later years makes it more important to highlight that methods often regarded as relating more to social science than to science can be part of inquiry (Chang Rundgren and Rundgren 2016).

Successful TPD needs to provide an opportunity for teachers to reflect on and learn about how new practices can evolve or be modified from existing classroom practice (Harrison, Hofstein, Eylon and Simon 2008). Furthermore, teachers need to familiarize themselves with new ideas and also understand the implications for themselves as teachers and for their students in the classroom before they adopt and adapt them. Heinz and colleagues show that, even though fundamental elements of IBSE is a common feature of the science instruction, curricula, and TPD in the countries participating in the S-TEAM project, the implementation of IBSE varies significantly between different countries. IBSE was shown to be part of teacher education and TPD modules in all the participating countries, but to varying degrees and in different forms. Furthermore, Heinz and her colleagues note that TPD modules on IBSE are offered by national organizations as well as private institutes and the duration of the TPDs can range from 1-day seminars to courses which take place over a longer period.

But how can TPD initiatives be made successful? In order to be successful, TPD initiatives need to be well adapted to the socio-cultural context of the teachers. What may work in one context does not necessarily work well in another educational context. Research into what makes TPD initiatives successful indicate that teachers generally need to experience new approaches for teaching within a carefully designed framework (Ostermeier, Prenzel and Duit 2010). Susan Loucks-Horsley, Katherine Stiles, Susan Mundry, Nancy Love, and Peter Hewson (2010, pp. 70-71) highlight important features that characterize successful TPD programs:

- Effective professional development is designed to address student learning goals and needs.

- Effective professional development experiences are driven by a well-defined image of effective classroom learning and teaching. This image includes, for example, a commitment to all children learning science, an emphasis on inquiry-based learning, investigations, problem solving, and applications of knowledge, an approach that emphasizes in-depth understanding of core concepts and challenges students to construct new understandings and clear means to measure meaningful achievement.

- Effective professional development experiences provide opportunities for teachers to build their content and pedagogical content knowledge and skills and examine and reflect on practice critically.

- Effective professional development experiences are research based and engage teachers as adult learners in the learning approaches they will use with their students.

- Effective professional development provides opportunities for teachers to work with colleagues and other experts in learning communities to continually enhance their practice.

- Effective professional development experiences support teachers to deepen their professional expertise throughout their career and serve in leadership roles.

- Effective professional development experiences provide links to other parts of the education system. 
- Effective professional development experiences are continuously evaluated to ensure a positive impact on teacher effectiveness, student learning, leadership, and the school community.

In all efforts to reform science education, teachers are key actors, and their professional knowledge, experiences and judgements must be taken into consideration to make any reform program successful (Ostermeier et al. 2010). According to Christian Ostermeier, Manfred Prenzel and Reinders Duit (2010), TPD can serve as a vehicle to convey researchbased educational knowledge into classrooms. At the same time, reforming science education can never be a question of simple implementation of theoretical ideas, the teachers must be part of negotiating and implementing change. Furthermore, teachers need to be given the chance to become subjects in reforming education rather than merely being subjected to reforms. Teachers need to be given the possibility to try out new ways to teach and develop their skills in the field (in this case IBSE) for change to take place. In the European tradition of Didaktik, teachers' professional judgement and choices are regarded as key factors in implementing educational reforms (Hudson 2002).

\section{Science as a global culture and global pressures towards isomorphism in education}

When following educational policy debates in different countries, one can often get the impression that the positive relationship between science education and economic development of a country seem to be more or less taken for granted. However, any causal relation between a country's level of education in science and economic progress has been shown to be difficult to establish (Drori 2000). Within the framework of neo-institutional comparative studies, the role of international organizations and world culture in the worldwide establishment of institutions such as science education has been highlighted. As Heinz and her colleagues stress in their article, there are currently increased global pressures towards isomorphism in science education. Some researchers have raised concerns about whether the science curricula used in developing countries really meet the educational needs of the people of those countries. In order to 'catch up' with industrialized countries, there has been a tendency among developing countries to 'cut and paste' from international science education initiatives (Drori 2000). Furthermore, Gili Drori and John Meyer (2006) raise the issue of 'scientization' of society and the spread of Western paradigms of rationality as a dominant global culture. It has been shown that science education curricula take similar forms: teaching similar subjects, prescribing similar modes of thinking and acting, a similar range of pursuable questions and a similar notion of who may take the role of a scientist (Drori 2000). There may thus be a global risk of losing valuable aspects of local traditions and cultural variation in education due to the efforts to keep pace with international competition as it is perceived by policy-makers.

Cultural heritage and long-standing traditions can provide both opportunities and challenges for developing education internationally. In a study by Ngô Vũ Thu Hằng, Marijn Roland Meijer, Astrid Bulte, and Albert Pilot (2015), the Confucian educational tradition in Vietnam is discussed in the context of implementation of social constructivist approaches in primary science education. Hằng et al. (2015) conclude that some of the characteristics of Confucian heritage culture, such as the high respect of teachers, parents, and theoretical knowledge (for instance about classical literature) can be at odds with ambitions to develop independent, creative students skilled in critical thinking, opinion- 
forming and argumentation. At the same time, education in Confucian heritage cultures (such as Vietnam, China, Taiwan, Singapore, Korea, and Japan) doubtlessly benefit greatly from the importance and respect attributed to education and learning in the Confucian tradition. The shared acceptance of this respect for education in society and the focus on education as the major way to make life better in the Confucian heritage cultures, regardless of social class and academic background of the family, can certainly be an enormous asset in the knowledge-intensive, globalized society of today. At the same time as we need to acknowledge the differences between different cultures and educational traditions in different countries, we must also be careful not to over-emphasize those differences. The basic structures of education are in many ways similar in schools all over the world. In her comment to Hằng et al.'s article, Shu-Nu Chang Rundgren (2015) emphasize that several of the characteristics of Vietnamese schools, such as textbookbased teaching and involvement of the family also are abundant features in Western schools, and therefore are hard to attribute to the Confucian heritage alone. Chang Rundgren (2015) highlights the Mandarin proverb The moon in a foreign country is more round, which can serve as a reminder when we make comparisons between educational systems in different countries. It may be easy to identify the positive sides of a foreign educational system, while it is easy to see the shortcomings of the educational system of your homeland. In my view, this selective way of looking at educational systems can be found in educational policy debates all over the world (commonly used with the intention to score political points). Thus, to increase our knowledge about the actual characteristics of education in different countries, more empirical studies are needed within the field of comparative education. It could be argued that we need to study in which ways different educational systems put different focus on different aspects of science education. But how can we study those differences, and how can we find out what are critical differences? Evident ways to make cross-country comparisons is to compare curricula, and also to make comparative textbook analyses. More demanding ways to study cross-national differences in science education is to make comparative classroom studies in order to find out whether the aspects of science education that are stressed in curricula and in textbooks really are the same aspects that are focused in actual classroom teaching. Raymond Williams (1973) has highlighted the existence of selective traditions, which can result in teaching traditions in schools being quite resistant to change, even if changes are made in the curricula.

An alternative way to study local cultural interests and needs regarding science and science education is to study the science content discussed in local media. The results from a study of the frequency of science-related terms in Taiwanese news media articles by Carl-Johan Rundgren, Shu-Nu Chang Rundgren, Yuen-Hsien Tseng, Pei-Ling Lin, and Chun-Yen Chang (2012) concerning the distribution of terms among different school subjects showed that biology/life science was the most highly represented subject area represented at $45 \%$. Earth science $(38 \%)$ was the second most frequently cited subject area, while physics (12\%) and chemistry (5\%) had markedly lower representations in the news media. The results also showed that the terms in biology were drawn mainly from molecular life science (e.g. biotechnology) and biomedical science (e.g. physiology and nutrition); these terms relate to human health issues, which was clearly an area of intense public interest in Taiwanese news media. The second most common subject area was that of earth science and seems to relate to the specific conditions of the local Taiwanese environment (with typhoons and earthquakes as common natural hazards). This and other studies show that news media is a resource which can be drawn upon in studies of what aspects of science that are discussed at a certain time in a certain country. Naturally, news media are created with different intentions than national curricula and textbooks, and we 
cannot assume that news media would be likely to cover all aspects of science that a society would deem as important for their citizens to learn. Still, news media can provide an additional source of information of what aspects of science that are debated in a certain society at a certain period of time, which can serve as a complement to analyses of curricula and textbooks.

\section{Concluding remarks}

In this forum article, I have reflected on some issues relating to the implementation of inquiry-based science education in different countries, and furthermore on some trends of current developments in science education internationally. Highlighting what Heinz and her colleagues call the policy of 'soft governance' of the EU regarding how to improve science education in Europe, I have discussed the focus on IBSE in the seventh framework projects funded by the EU, and how it is possible to maintain more long-lasting results in schools through well-designed teacher professional development programs. Shifting the focus from a mainly European context also into a more global perspective, Heinz and her colleagues also highlight how global pressures on convergence in education interact with educational structures and traditions in the individual countries. Heinz and her colleagues try to interpret those developments in the light of neo-institutional theories, relating to global pressures towards isomorphism in science education as well as the spread of Western paradigms of rationality over the world. In my view, the rise of science and science education as a global culture, encompassing contributions from all around the world, is a phenomenon of enormous potential and great value to humankind. However, it is important to bear in mind that if science and science education is going to become a truly global culture, local variation and differences regarding foci and applications of science in different cultures must be acknowledged. Even though science at its core may remain the same all around the world, science education cannot and should not be the same all over the world. Cultural differences in how science education is conducted in different countries does not only relate to superficial features, but is related to the very heart of what science education means.

Open Access This article is distributed under the terms of the Creative Commons Attribution 4.0 International License (http://creativecommons.org/licenses/by/4.0/), which permits unrestricted use, distribution, and reproduction in any medium, provided you give appropriate credit to the original author(s) and the source, provide a link to the Creative Commons license, and indicate if changes were made.

\section{References}

Abd-El-Khalick, F., BouJaoude, S., Duschl, R., Lederman, N. G., Mamlok-Naaman, R., Hofstein, A., et al. (2004). Inquiry in science education: International perspectives. Science Education, 88, 397-419. doi:10.1002/sce.10118.

Bergqvist, K., \& Säljö, R. (1994). Conceptually blindfolded in the optics laboratory. Dilemmas of inductive learning. European Journal of Psychology of Education, 9, 149-158. doi:10.1007/BF03173550.

Biesta, G. (2007). Why "what works" won't work: Evidence-based practice and the democratic deficit in educational research. Educational Theory, 57, 1-22. doi:10.1111/j.1741-5446.2006.00241.x.

Chang Rundgren, S. N. (2015). 'Is the moon more round in the Western world?'-Some important aspects of comparative education. Cultural Studies of Science Education, 10, 707-718. doi:10.1007/s11422014-9635-7.

Chang Rundgren, S. N., \& Rundgren, C.-J. (2016). What are we aiming for?-A Delphi study on the development of civic scientific literacy in Sweden. Scandinavian Journal of Educational Research, . doi:10.1080/00313831.2015.1120231. 
Drori, G. S. (2000). Science education and economic development: Trends, relationships, and research agenda. Studies in Science Education, 35, 27-57. doi:10.1080/03057260008560154.

Drori, G. S., \& Meyer, J. W. (2006). Scientization: Making a world safe for organizing. In M.-L. Djelic \& K. Sahlin-Andersson (Eds.), Transnational governance. Institutional dynamics of regulation (pp. 31-52). Cambridge: Cambridge University Press.

Furtak, E. M., Seidel, T., Iverson, H., \& Briggs, D. C. (2012). Experimental and quasi-experimental studies of inquiry-based science teaching: A meta-analysis. Review of Educational Research, 82, 300-329. doi: $10.3102 / 0034654312457206$.

George, R. (2006). A cross-domain analysis of change in students' attitudes toward science and attitudes about the utility of science. International Journal of Science Education, 28, 571-589. doi:10.1080/ 09500690500338755.

Hằng, N. V. T., Meijer, M. R., Bulte, A. M. W., \& Pilot, A. (2015). The implementation of a social constructivist approach in primary science education in Confucian heritage culture: The case of Vietnam. Cultural Studies of Science Education, 10, 665-693. doi:10.1007/s11422-014-9634-8.

Harrison, C., Hofstein, A., Eylon, B., \& Simon, S. (2008). Evidence based professional development of science teachers in two countries. International Journal of Science Education, 30, 577-591. doi:10. $1080 / 09500690701854832$.

Hudson, B. (2002). Holding complexity and searching for meaning: Teaching as reflective practice. Journal of Curriculum Studies, 34, 43-57. doi:10.1080/00220270110086975.

Jidesjö, A., Oscarsson, M., Karlsson, K.-G., \& Strömdahl, H. (2009). Science for all or science for some: What Swedish students want to learn about in secondary science and technology and their opinions on science lessons. NorDiNa Nordic Studies in Science Education, 5, 214-229.

Kirschner, P. A., Sweller, J., \& Clark, R. E. (2006). Why minimal guidance during instruction does not work: An analysis of the failure of constructivist, discovery, problem-based, experiential, and inquirybased teaching. Educational Psychologist, 41, 75-86. doi:10.1207/s15326985ep4102_1.

Lederman, J. S., Lederman, N. G., Bartos, S. A., Bartels, S. L., Meyer, A. A., \& Schwartz, R. S. (2014). Meaningful assessment of learners' understandings about scientific inquiry-The views about scientific inquiry (VASI) questionnaire. Journal of Research in Science Teaching, 51, 65-83. doi:10.1002/tea. 21125.

Loucks-Horsley, S., Stiles, K. E., Mundry, S., Love, N., \& Hewson, P. W. (2010). Designing professional development for teachers of science and mathematics. Thousand Oaks, CA: Corwin. doi:10.4135/ 9781452219103.

Lunde, T., Rundgren, C.-J., \& Chang Rundgren, S. N. (2015). När läroplan och tradition möts - hur högstadielärare bemöter yttre förväntningar på undersökande arbete i naturämnesundervisningen. [How lower secondary science teachers meet external expectations on inquiry-based science teaching]. NorDiNa (Nordic Studies in Science Education), 11, 88-101.

Oscarsson, M., Jidesjö, A., Strömdahl, H., \& Karlsson, K.-G. (2009). Science in society or science in school: Swedish secondary school science teachers' beliefs about science and science lessons in comparison with what their students want to learn. NorDiNa Nordic Studies in Science Education, 5, 18-34.

Ostermeier, C., Prenzel, M., \& Duit, R. (2010). Improving science and mathematics instruction: The SINUS project as an example for reform as teacher professional development. International Journal of Science Education, 32, 303-327. doi:10.1080/09500690802535942.

Rocard, M., Csermely, P., Jorde, D., Lenzen, D., Walberg-Henriksson, H., \& Hemmo, V. (2007). Science education now. A renewed pedagogy for the future of Europe. European Commission. http://ec.europa. eu/research/science-society/document_library/pdf_06/report-rocard-on-science-education_en.pdf.

Rundgren, C.-J., Chang Rundgren, S.-N., Tseng, Y.-H., Lin, P.-L., \& Chang, C.-Y. (2012). Are you SLiM? - The development of an instrument for civic scientific literacy measurement (SLiM) based on media coverage. Public Understanding of Science, 21, 759-773. doi:10.1177/0963662510377562.

Stenhouse, L. (1979). Case study in comparative education: Particularity and generalisation. Comparative Education, 15, 5-10. doi:10.1080/0305006790150102.

Williams, R. (1973). Base and superstructure in marxist cultural theory. New Left Review, 82, 3-16.

Zeidler, D. (1997). The central role of fallacious thinking in science education. Science Education, 81, 483496. doi:10.1002/(SICI)1098-237X(199707)81:4<483:AID-SCE7 > 3.0.CO;2-8.

Carl-Johan Rundgren is an associate professor in science education at the Department of Science and Mathematics Education, Stockholm University, Sweden. His main research interest relates to development of scientific literacy and different ways to represent science content. 